\title{
Cariprazine: Patients with Treatment-Resistant Schizophrenia
}

\section{Thomas Aubel}

Kliniken Essen-Mitte, Klinik für Psychiatrie, Psychotherapie, Psychosomatik und Suchtmedizin, Essen, Germany
Correspondence: Thomas Aubel Kliniken Essen-Mitte, Klinik für Psychiatrie, Psychotherapie, Psychosomatik und Suchtmedizin, Henricistraße 92, Essen, 45।36, Germany Tel +4920II7430005

Email T.Aubel@kem-med.com
Abstract: Schizophrenia is a chronic relapsing and remitting disorder associated with significant impairments in social and vocational functioning and a shortened lifespan, and it is a disabling psychiatric brain syndrome whose phenotype is characterized by three core symptom domains: positive symptoms, such as delusions and hallucinations, negative symptoms, which include lack of motivation and social withdrawal, and cognitive impairment. Moreover, patients with schizophrenia have severe problems with personal and social relations which affect their quality of life. Antipsychotic medications in conjunction with psychosocial interventions can help patients achieve recovery. Here are described three clinical cases of schizophrenic patients treated with cariprazine for inadequate response to a previous treatment. The purpose of this clinical series is to give useful information for the use of cariprazine in clinical practice.

Keywords: cariprazine, schizophrenia, paranoid schizophrenia, negative symptoms, resistant schizophrenia, antipsychotics

\section{Introduction}

Schizophrenia is a severe, chronic mental condition that requires long-term treatment. ${ }^{1}$ It is a heterogeneous mental disorder, with no single pathognomonic symptom or presentation, characterized by a constellation of signs and symptoms that are divided into three core symptom domains: positive, negative, and cognitive. Pharmacologic therapy is a central part of schizophrenia management and antipsychotics are the first-line medication for this psychiatric disorder.

Cariprazine is a new D3/D2 partial agonist antipsychotic with preferential binding to D3 receptors ${ }^{2,3}$ (Table 1) and its efficacy in the treatment of schizophrenia has been demonstrated by several trials. ${ }^{4-11}$ Due to its specific profile, cariprazine is expected to predominately control negative symptoms, but its longterm efficacy in the prevention of disease relapse has been demonstrated as well. ${ }^{8}$ Common side effects include motor symptoms, restlessness and GI symptoms, albeit it is generally considered to be well tolerated. As of today, the number of novel treatments targeting schizophrenia is increasing. ${ }^{12}$ Cariprazine has the potential to be of additional value, thanks to its unique receptor profile and its good tolerability. Its beneficial effects have recently also been reported outside of schizophrenia. $^{13}$

The efficacy of Cariprazine in treatment-refractory schizophrenia remains to be systematically investigated. Here we report three clinical cases of schizophrenia patients who responded to cariprazine after inadequate responses to previous 
Table I Binding Affinities of Cariprazine and the Clinical Properties of the Receptors. Cariprazine Shows High Affinity for D3, D2 and 5-HTIA Receptors, Moderate Affinity for 5-HT2A and HI Receptors and Low Affinity for 5-HT2C and $\alpha$ IA Receptors

\begin{tabular}{|l|c|c|c|l|}
\hline Receptor & Action $^{\mathbf{2 , 2 1}}$ & Affinity $^{\mathbf{2 2}}$ & Ki Value (nM) $^{\mathbf{2 3}}$ & Pharmacodynamic Effects $^{\mathbf{2 4}}$ \\
\hline D3 & Partial agonist & High $(<10 \mathrm{nM})$ & 0.085 & Antipsychotic (including negative symptoms) \\
D2L & Partial agonist & High $(<10 \mathrm{nM})$ & 0.49 & Antipsychotic \\
D2S & Partial agonist & High $(<10 \mathrm{nM})$ & 0.69 & Antipsychotic \\
5-HTIA & Partial agonist & High $(<10 \mathrm{nM})$ & 3.0 & Antidepressant \\
5-HT2A & Antagonist & Moderate $(10-100 \mathrm{nM})$ & 19.0 & Anti-EPS \\
HI & Antagonist & Moderate $(10-100 \mathrm{nM})$ & 23.0 & Anxiolytic, anti-insomnia \\
5-HT2C & Antagonist & Low $(>100 \mathrm{nM})$ & 134 & Antidepressant \\
$\alpha$ IA & Antagonist & Low $(>100 \mathrm{nM})$ & 155 & Antihypertensive \\
\hline
\end{tabular}

treatments. The first two cases fulfill the expert consensus of treatment-refractory schizophrenia, defined as failure to two attempts of adequate antipsychotic medical treatment, whereas the third case describes a patient at high risk of a treatment-refractory course of disease. ${ }^{14}$

\section{Case I: Cariprazine Replaces Electroconvulsive Therapy (ECT) for the Treatment of Negative Symptoms of \\ Paranoid Schizophrenia}

This case report describes a successful switch to cariprazine in a patient with paranoid schizophrenia (ICD10), after multiple medication changes and electroconvulsive therapy failed to adequately control positive, as well as negative symptoms.

The patient is a 59-year-old lady, early retired, married with no children. Eldest of three children, at the age of 16 the patient was affected by her parent's separation and the subsequent suicide of her father. In age 30 , she was first diagnosed with paranoid schizophrenia whose chief complaint at that time was avolition. Between 1990 and 2002, the patient had three severe episodes of disease exacerbation each one requiring inpatient treatment for several months. Leading complaints were pronounced negative symptoms with severe psychomotor retardation and delusional thoughts, like the feeling of being observed by the neighbors. She received various drug treatments and suffered sometimes severe somatic complications, such as pulmonary embolism after deep vein thrombosis. Neither the combination therapy of flupentixol $10 \mathrm{mg}$, mirtazapine $45 \mathrm{mg}$, and lorazepam $1.5 \mathrm{mg}$ for 4 weeks nor olanzapine $20 \mathrm{mg}$, aripiprazole $15 \mathrm{mg}$, haloperidol $10 \mathrm{mg}$, mirtazapine $45 \mathrm{mg}$, and lorazepam $6 \mathrm{mg}$ for 6 weeks were able to effectuate significant improvements in her negative and delusional symptoms. After her psychomotor drive deteriorated further and the patient became progressively bedridden, ECT was performed. After 5 courses of ECT there was no adequate treatment response and the patient, who was now fully bedridden, suffered subsequently from deep vein thrombosis, pulmonary artery embolism and infarct pneumonia. After a drug pause and intravenous treatment with lorazepam $3 \times 2 \mathrm{mg}$ daily, there was a switch to risperidone, starting at $2 \times 0.5 \mathrm{mg}$ and later increased to $2 \times 1 \mathrm{mg}$ daily, which did not result in any significant improvement either. Psychomotor drive remained massively reduced with continued bedriddenness.

Cariprazine was initiated with a starting dose of $1.5 \mathrm{mg}$ daily, increased to $3 \mathrm{mg}$ daily after three days and to $4.5 \mathrm{mg}$ daily after two weeks while risperidone was tapered to $2 \times 0.5 \mathrm{mg}$ daily and eventually discontinued. The patient tolerated the medication well and her symptoms improved significantly. After 4.5 months of treatment, the patient did not experience any more delusions and psychomotor drive. Negative symptoms were significantly improved, and the patient was discharged.

Four weeks after discharge, the patient, now on cariprazine $4.5 \mathrm{mg}$ daily and rivaroxaban $20 \mathrm{mg}$ daily for prevention of deep vein thrombosis, was mentally stable and took care of her household independently.

\section{Case 2: Cariprazine for Paranoid Schizophrenia with Pronounced Negative Symptoms}

This case report presents the successful medication switch from olanzapine/clozapine to cariprazine in a 31-year-old patient suffering from severe paranoid schizophrenia.

The 31-year-old patient was initially diagnosed with paranoid-hallucinatory schizophrenia (ICD10) in 2010. At that time, he experienced predominantly severe negative 
symptoms and psychomotor retardation. The patient lived by himself and failed repeatedly to complete his studies due to the disease. His social contacts were limited to his mother and his two older siblings; there was no family history of mental illness. His past psychiatric history included five severe episodes, each lasting for several months, characterized by acute psychotic symptoms, severe drive disorders, flattening of the formal thought disorders, and leading to several inpatient stays.

The patient was first prescribed olanzapine 10$0-10 \mathrm{mg}$ in 2010 . After an attempt to reduce the dose to $2.5 \mathrm{mg}$ daily in 2013, he experienced a relapse which required weeks of inpatient treatment and a subsequent dose increase to $20 \mathrm{mg} /$ daily. After olanzapine discontinuation on his own account, we attempted to switch to clozapine 50-50-100 mg per day. In 2015, he was admitted with an acute psychotic symptom exacerbation after he discontinued his medication again. He was then administered clozapine under the supervision of the hospital nursing staff. In 2018, the patient stopped taking clozapine again and was admitted to the hospital. Clozapine was started once again, but eventually combined with amisulpride up to $300 \mathrm{mg}$ /daily amid a massive decompensation and gradually persistent negative symptoms. Symptoms did not improve and his drive remained reduced.

In 2019, we initiated a treatment attempt with cariprazine in addition to the existing combination therapy of clozapine and amisulpride. Initial starting dose of cariprazine was $1.5 \mathrm{mg}$ daily, which was increased to $3 \mathrm{mg}$ daily after three days. We could subsequently taper off and discontinue amisulpride, whilst continuously administering clozapine $100 \mathrm{mg}$ daily. After 2 months of remission of psychotic symptoms we can reduce clozapine to $75 \mathrm{mg}$. As the patient reported a significant improvement in psychomotor drive and mood, we increased cariprazine dosage to $4.5 \mathrm{mg}$ daily and further reduced clozapine to $50 \mathrm{mg}$ daily. Our aim was mono therapy. In September 2019, the patient was in complete remission and clozapine could be discontinued and he eventually registered for the final study exam.

\section{Case 3: Acute Treatment and Desired Switch to Cariprazine}

This case report describes the use of cariprazine in a patient with acute psychotic decompensation. Cariprazine was initiated upon the patient's own request.
A rapid updosing scheme was used, as the patient wanted to be discharged from the hospital quickly.

This was a 32-year-old male patient from Sudan. He has been living in Germany for two years, he lived alone and worked as a doctor in a neurological rehabilitation clinic. He had previously worked as a resident in a psychiatric clinic for 6 months but had quit due to working conditions. The patient reported having had psychotic episodes as early as 17 during military service. However, these had not been further evaluated and he himself had attributed them to an underlying iron deficiency anemia.

The patient was diagnosed with paranoid schizophrenia (ICD10) in 2018. Since the first psychotic symptoms had occurred at 17 years of age, an even longer duration of illness can be assumed. He suffered other psychotic episodes in 2018 and 2019, in September 2018 after consumption of cannabis on the previous day. He experienced recurrent paranoid episodes with ideas of reference and persecutory delusions, and he was also increasingly suspicious. There were no formal thought disorders. His main concern, however, was his increasingly impaired concentration, which made working very difficult for him. Head MRI from August 2018 reported mild cortical atrophy as well as microangiopathic lesions and a small uncharacteristic lesion on the right temporomesial side without signs of space occupation.

Most recently, the patient presented to our emergency room with paranoid ideas that had been present for three days. At time of admission, he was alert, oriented to person, place and time, friendly. He was in a euthymic mood with intermittent suicidal thoughts but no suicide attempt. Moreover, he was able to agree to therapy.

Patient was admitted to the open inpatient ward for a psychotic disorder and took part in a multimodal therapy concept with individual and group psychological therapies. Pharmacological therapy consisted in risperidone $1 \mathrm{mg}$ twice a day increased to $2 \mathrm{mg}$ twice a day during treatment. Therapy was switched to aripiprazole $10 \mathrm{mg}$ with simultaneous reduction to $0.5 \mathrm{mg}$ risperidone on patient's request. After discussing treatment options with this medically knowledgeable patient, cariprazine was initiated at $1.5 \mathrm{mg} /$ day (day 1), while aripiprazole $10 \mathrm{mg}$ and risperidone $0.5 \mathrm{mg}$ were discontinued, and gradually increased to $3 \mathrm{mg}$ (day 2) and $4.5 \mathrm{mg}$ (day 3). Cariprazine was very well tolerated with complete resolution of psychotic symptoms and improvement in cognitive performance, concentration, and alertness. No recurrence of akathisia 
developed while on aripiprazole nor other forms of agitation were reported. The patient remained on $4.5 \mathrm{mg}$ cariprazine and he was able to resume work in the clinic as a resident with no complaint of any impairment of his performance and psychotic symptoms no longer occurred.

\section{Discussion}

Schizophrenia is a chronic and disabling disorder, characterized by heterogeneous positive and negative symptom constellations. ${ }^{15}$ While positive symptoms reflect an excess or distortion of normal function (eg, delusions, hallucinations, disorganized behavior), negative symptoms refer to a diminution or absence of normal behaviors related to motivation and interest (eg, avolition, anhedonia, asociality) or expression (eg, blunted affect, alogia). ${ }^{16}$

Schizophrenia requires lifelong treatment, even when symptoms have subsided. Treatment with medications and psychosocial therapy can help manage the condition and, in some cases, hospitalization may be needed.

Cariprazine is a new atypical antipsychotic approved by the European Medicines Agency for the management of schizophrenia. ${ }^{17}$ Cariprazine acts as a D2 and D3 receptor partial agonist with a higher affinity for the D3 receptor, which differs from current antipsychotics. ${ }^{18}$ In addition to potent partial agonist activity at D3 and D2 receptors, cariprazine also acts as an antagonist at the serotonin 5-HT2B receptors, a partial agonist at 5-HT1A receptors, and shows lower or negligible affinity at other receptors, including noradrenergic, histaminergic, and cholinergic receptors. ${ }^{11}$

Clinical results to date from several schizophrenia trials clearly demonstrated that cariprazine is effective and well tolerated. Cariprazine was significantly more effective than placebo for the treatment of acute schizophrenia in all symptom domains. ${ }^{4-7}$ Moreover, a clinical trial supported the efficacy of cariprazine in the treatment of predominant negative symptoms. Patients given cariprazine had a greater improvement in negative symptoms of schizophrenia than did patients given risperidone. Patients receiving cariprazine also had a greater improvement in functioning, suggesting that improvement in negative symptoms translated to improved community functioning for these patients. ${ }^{9}$ Furthermore, open-label extension studies support the long-term safety and tolerability of cariprazine in patients with acute exacerbation of schizophrenia ${ }^{10,11}$ reinforcing the findings observed in the double-blind studies. In addition, in the relapse prevention study ${ }^{8}$ long-term cariprazine treatment was significantly more effective than placebo for relapse prevention in patients with schizophrenia.

In our experience, a targeted medical approach with cariprazine, combined with behavioral interventions, is a promising treatment option even after multiple previous medical treatments have failed. In the first case, the therapeutic breakthrough was achieved with the switch to cariprazine. After increasing the cariprazine dosage to $4.5 \mathrm{mg} / \mathrm{day}$, the patient showed a significant improvement in her symptoms within a few weeks. Eventually psychomotor drive and negative symptoms further improved. Cariprazine was well tolerated and risperidone was discontinued. After 4.5 months of treatment, the patient was free of delusional symptoms and was able to be discharged. In the second patient cariprazine finally brought the hoped-for treatment success. Cariprazine was administered at starting dose of $1.5 \mathrm{mg}$ in combination with clozapine and after three days increased to $3 \mathrm{mg}$ and then to $4.5 \mathrm{mg}$. After the patient's symptoms improved, the combined treatment with cariprazine and clozapine was continued as an outpatient. Within only 2 months, the symptoms improved significantly, and clozapine could be reduced and then discontinued. The last case describes long-standing, severe paranoid-hallucinatory schizophrenia with pronounced negative symptoms where a switch to cariprazine led to a treatment success in combination with psychological therapies. Cariprazine was initiated, upon patient's own request, at $1.5 \mathrm{mg} / \mathrm{day}$, increased to $3 \mathrm{mg}$ on day 2 and to $4.5 \mathrm{mg}$ on day 3 . The treatment was excellently tolerated, and the symptoms subsided quickly. Patient remained on cariprazine $4.5 \mathrm{mg}$ and was able to resume work in the clinic as a resident and to achieve and maintain a satisfactory lifestyle.

\section{Conclusion}

Cariprazine is a new antipsychotic effective in the treatment of schizophrenia and thanks to its peculiar receptor profile with a D2/D3 partial agonist and high D3 affinity it is effective on the entire spectrum of symptoms of schizophrenia. ${ }^{19,20}$ The cases described highlight several problems of real-life schizophrenia management and show the beneficial effect of cariprazine in patients with an inadequate response to a previous medication. A tailored approach can be a therapeutic breakthrough for the treatment of patients with schizophrenia. 


\section{Consent for Publication}

Kliniken Essen-Mitte, Klinik für Psychiatrie, Psychotherapie, Psychosomatik und Suchtmedizin ethics committee approved the clinical cases publication and Informed consent was obtained from the patients.

\section{Disclosure}

Dr. Thomas Aubel has received honoraria for scientific talks and participation in advisory boards from JanssenCilag, Lundbeck, Otsuka Pharma, Servier, Lilly and Recordati Pharma. Recordati provided financial support for the writing of the manuscript.

\section{References}

1. Mueser KT, McGurk SR. Schizophrenia. Lancet. 2004;363 (9426):2063-2072. doi:10.1016/S0140-6736(04)16458-1

2. Kiss B, Horváth A, Némethy Z, et al. Cariprazine (RGH-188), a dopamine $\mathrm{D}(3)$ receptor-preferring, $\mathrm{D}(3) / \mathrm{D}(2)$ dopamine receptor antagonist-partial agonist antipsychotic candidate: in vitro and neurochemical profile. J Pharmacol Exp Ther. 2010;333(1):328-340. doi:10.1124/jpet.109.160432

3. Girgis RR, Slifstein M, D'Souza D, et al. Preferential binding to dopamine D3 over D2 receptors by cariprazine in patients with schizophrenia using PET with the D3/D2 receptor ligand [(11)C]-(+)-PHNO. Psychopharmacology (Berl). 2016;233(19-20):3503-3512. doi:10.1007/s00213-016-4382-y

4. Durgam S, Litman RE, Papadakis K, et al. Cariprazine in the treatment of schizophrenia: a proof-of-concept trial. Int Clin Psychopharmacol. 2016;31(2):61-68. doi:10.1097/YIC.0000000000000110

5. Durgam S, Starace A, Li D, et al. An evaluation of the safety and efficacy of cariprazine in patients with acute exacerbation of schizophrenia: a Phase II, randomized clinical trial. Schizophr Res. 2014;152 (2-3):450-457. doi:10.1016/j.schres.2013.11.041

6. Durgam S, Cutler AJ, Lu K, et al. Cariprazine in acute exacerbation of schizophrenia: a fixed-dose, Phase 3, randomized, double-blind, placebo- and active-controlled trial. J Clin Psychiatry. 2015;76(12): e1574-82. doi:10.4088/JCP.15m09997

7. Kane JM, Zukin S, Wang Y, et al. Efficacy and safety of cariprazine in acute exacerbation of schizophrenia: results from an international, phase III clinical trial. J Clin Psychopharmacol. 2015;35(4):367-373. doi:10.1097/JCP.0000000000000346

8. Durgam S, Earley W, Li R, et al. Long-term cariprazine treatment for the prevention of relapse in patients with schizophrenia: a randomized, double-blind, placebo-controlled trial. Schizophr Res. 2016;176(23):264-271. doi:10.1016/j.schres.2016.06.030

9. Németh G, Laszlovszky I, Czobor P, et al. Cariprazine versus risperidone monotherapy for treatment of predominant negative symptoms in patients with schizophrenia: a randomised, double-blind, controlled trial. Lancet. 2017;389(10074):1103-1113. doi:10.1016/S01406736(17)30060-0
10. Durgam S, Greenberg WM, Li D, et al. Safety and tolerability of cariprazine in the long-term treatment of schizophrenia: results from a 48-week, single-arm, Open-Label Extension Study. Psychopharmacology (Berl). 2017;234(2):199-209. doi:10.1007/ s00213-016-4450-3

11. Cutler AJ, Durgam S, Wang Y, et al. Evaluation of the long-term safety and tolerability of cariprazine in patients with schizophrenia: results from a 1-Year Open-Label Study. CNS Spectr. 2018;23 (1):39-50. doi:10.1017/S1092852917000220

12. Orsolini L, De Berardis D, Volpe U. Up-to-date expert opinion on the safety of recently developed antipsychotics. Expert Opin Drug Saf. 2020;19(8):981-998. Epub 2020 Jul 21. PMID: 32657173. doi:10.1080/14740338.2020.1795126

13. De Berardis D, Vellante F, Fornaro M, et al. Rapid improvement of obsessive-compulsive disorder associated with schizophrenia with cariprazine add-on in a subject under paliperidone long-acting injection: a case report. Int Clin Psychopharmacol. 2020;35(2):113-118. PMID: 32004167. doi:10.1097/YIC.0000000000000284

14. Potkin SG, Kane JM, Correll CU, et al. The neurobiology of treatment-resistant schizophrenia: paths to antipsychotic resistance and a roadmap for future research. NPJ Schizophr. 2020;6(1). doi:10.1038/s41537-019-0090-z

15. Kahn RS, Sommer IE, Murray RM, et al. Schizophrenia. Nat Rev Dis Primers. 2015;1(1):15067. doi:10.1038/nrdp.2015.67

16. Correll CU, Schooler NR. Negative symptoms in schizophrenia: a review and clinical guide for recognition, assessment, and treatment. Neuropsychiatr Dis Treat. 2020;16:519-534. doi:10.2147/ NDT.S225643

17. European Medicines Agency Reagila Assessment Report. 2017. Available from: https:/www.ema.europa.eu/en/documents/assess ment-report/reagila-epar-public-assessment-report_en.pdf. Accessed July 9, 2021.

18. Stahl SM. Mechanism of action of cariprazine. CNS Spectr. 2016;21 (2):123-127. doi:10.1017/S1092852916000043

19. Chhatlani A, Farheen SA, Setty MJ, et al. Use of cariprazine in psychiatric disorders: a systematic review. Ann Clin Psychiatry. 2018;30(4):326-334.

20. Citrome L. Cariprazine for the treatment of schizophrenia: a review of this dopamine D3-preferring D3/D2 receptor partial agonist. Clin Schizophr Relat Psychoses. 2016;10(2):109-119. doi:10.3371/19351232-10.2.109

21. Stahl SM. Stahl's Essential Psychopharmacology. 4th ed. 1996.

22. De Deurwaerdère P. Cariprazine: Newdopamine biased agonist for neuropsychiatric disorders. Drugs Today (Barc). 2016;52(2):97-110. doi:10.1358/dot.2016.52.2.2461868

23. Ki values have been taken from the PDSD Ki database. Available from: https://pdsp.unc.edu/databases/pdsp.php. Accessed July 9, 2021.

24. Frankel JS, Schwartz TL. Brexpiprazole and cariprazine: distinguishing two new atypical antipsychotics from the original dopamine stabilizer aripiprazole. Ther Adv Psychopharmacol. 2017;7 (1):29-41. doi:10.1177/2045125316672136 


\section{Publish your work in this journal}

Neuropsychiatric Disease and Treatment is an international, peerreviewed journal of clinical therapeutics and pharmacology focusing on concise rapid reporting of clinical or pre-clinical studies on a range of neuropsychiatric and neurological disorders. This journal is indexed on PubMed Central, the 'PsycINFO' database and CAS, and is the official journal of The International Neuropsychiatric Association (INA). The manuscript management system is completely online and includes a very quick and fair peer-review system, which is all easy to use. Visit http://www.dovepress.com/testimonials.php to read real quotes from published authors. 